\title{
Mathematical Verification for Transmission Performance of Centralized Lightwave WDM-RoF-PON with Quintuple Services Integrated in Each Wavelength Channel
}

\author{
Shuai Chen, ${ }^{1}$ Wei Nai, ${ }^{2,3}$ Fangqi Zhang, ${ }^{1,3}$ Shaoyin Wang, ${ }^{4}$ Decun Dong, ${ }^{1,3}$ and Yi Yu ${ }^{3}$ \\ ${ }^{1}$ The Key Laboratory of Road and Traffic Engineering, Tongji University, Ministry of Education, Shanghai 201804, China \\ ${ }^{2}$ Postdoctoral Research Station of Control Science and Engineering, Tongji University, Shanghai 201804, China \\ ${ }^{3}$ The Cooperative Center for Maglev and Rail Transit Operation Control System, Tongji University, Shanghai 201804, China \\ ${ }^{4}$ Tongii Zhejiang College, Jiaxing, Zhejiang 314051, China
}

Correspondence should be addressed to Wei Nai; alexni@tongji.edu.cn

Received 3 October 2015; Accepted 2 December 2015

Academic Editor: Vasily Spirin

Copyright (C) 2015 Shuai Chen et al. This is an open access article distributed under the Creative Commons Attribution License, which permits unrestricted use, distribution, and reproduction in any medium, provided the original work is properly cited.

\begin{abstract}
Wavelength-division-multiplexing passive-optical-network (WDM-PON) has been recognized as a promising solution of the "last mile" access as well as multibroadband data services access for end users, and WDM-RoF-PON, which employs radio-over-fiber (RoF) technique in WDM-PON, is even a more attractive approach for future broadband fiber and wireless access for its strong availability of centralized multiservices transmission operation and its transparency for bandwidth and signal modulation formats. As for multiservices development in WDM-RoF-PON, various system designs have been reported and verified via simulation or experiment till now, and the scheme with multiservices transmitted in each single wavelength channel is believed as the one that has the highest bandwidth efficiency; however, the corresponding mathematical verification is still hard to be found in state-of-theart literature. In this paper, system design and data transmission performance of a quintuple services integrated WDM-RoF-PON which jointly employs carrier multiplexing and orthogonal modulation techniques, have been theoretically analyzed and verified in detail; moreover, the system design has been duplicated and verified experimentally and the theory system of such WDM-RoF-PON scheme has thus been formed.
\end{abstract}

\section{Introduction}

WDM-PON can be recognized as the optimal choice for fiber access in fiber-to-the-home (FTTH) era, for it provides unprecedented bandwidth, and it can handle high reliability as well as high rate data transmission services [1]. With these advantages mentioned above, the proliferation of broadband data services in WDM-PON is surely a trend requested not only by end users, but by the information age as well. It is of no doubt that, in order to realize the transmission of multibroadband data services in WDM-PON, more independent data transmission channels without interfering each other should be provided in smaller limited bandwidth resources. Setting trunked wavelengths around certain wavelength range to transmit multiservices is a solution of that; apart from that, certain techniques that are applied in optical switching network including orthogonal modulation and carrier multiplexing have also been employed in WDM-PON so as to realize the transmission of multiservice around each central wavelength [2-4].

Even if WDM-PON has been recognized as a promising solution of the "last mile" access as well as multibroadband data services access for end users, the ever-increasing requirements during recent years for $3 \mathrm{~A}$ access mobility (anytime, anywhere, any media) still cannot be properly met [5]. Radioover-fiber (RoF) technique is an attractive approach for future broadband fiber and wireless access for its strong availability of centralized multiservices transmission operation and its transparency for bandwidth and signal modulation formats [6]. WDM-RoF-PON, which applies RoF technique in the terminal wireless access part of WDM-PON, can modulate or demodulate baseband and wireless signal simultaneously in 
the same wavelength channel [7]. It can be easily seen that WDM-RoF-PON can not only utilize the huge bandwidth resources of WDM-PON but also provide higher reliability and higher quality of broadband data service access for each wireless terminal and its transparency for bandwidth and modulation techniques which would be easier for system upgrade. Integrating quintuple services in each wavelength channel of WDM-RoF-PON [8] is believed as the most cost-effective and simplest scheme in signal modulation and demodulation; it fuses orthogonal modulation and carrier multiplexing techniques and can realize higher multiservices data transmission rate in a limited single wavelength channel.

Although the scheme of WDM-RoF-PON with quintuple services integrated in each of its wavelength channels has already been verified by simulation and experiment [8], the necessary mathematical verification has still not been reported anywhere. In this paper, the first effort to make theoretical description of the WDM-RoF-PON system with quintuple services integrated has been done, and the data transmission performance of both downstream and upstream services has been verified mathematically. By referring to related work, the system design has been duplicated and the effectiveness of the system design has been verified, and the theory system of such WDM-RoF-PON has thus been formed.

\section{Literature Review}

2.1. On System Design of Multiservices WDM-PON. As it has been discussed above, one important advantage of WDMPON system is that it has huge bandwidth resources which can be provided for multibroadband data services access. In WDM-PON, each end user has his own particular bandwidth resource; therefore, it is a key problem to design certain schemes which can properly and cost-effectively realize multiservice access in each wavelength channel. Consider that the optical sources and devices are main causes for high system costs; Park et al. [9] have tried to use low-cost amplified spontaneous emission (ASE) injected Fabry-Perot lasers as system light sources, while Zhang et al. [10] have made a system design with only a super continuum source to serve as the light sources for all wavelength channels; apart from the light sources, it is worth mentioning that remodulation technique is widely used in loading upstream data of multiservices WDM-PON so as to save local optical sources in optical network units (ONUs) according to related reports; Yu et al. [11] have employed OOK remodulation scheme in the DPSK signal modulated central peak of carrier multiplexed double side band (DSB) downstream spectrum to load point to point (P2P) upstream service data; Huang et al. [12] have tried to use reflective semiconductor optical amplifier (RSOA) in each ONU to realize remodulation of upstream data. As it comes to the realization of bidirectional multiservices in WDM-PON, Luo et al. [13] have set a specific wavelength channel $\lambda_{N+1}$ apart from other $N$ wavelength channels that correspond to $N$ ONUs in WDM-PON system so as to transmit broadcast service separately; Nai and Dong [14] have proposed an easily applicable, high bandwidth efficiency triple play services WDM-PON scheme with two downstream services orthogonally modulated in DPSK/FSK format and an upstream service remodulated in OOK format in the same wavelength channel; Tian and Su [15] have proposed a quadruple service integrated WDM-PON scheme with three carrier multiplexed downstream services and an upstream service, while Llorente et al. [16] have proposed a WDM-PON scheme with quintuple services bidirectionally transmitted in five different trunked wavelengths around certain wavelength range of each ONU.

2.2. On System Design of Multiservices RoF System. RoF technique has many advantages in providing $3 \mathrm{~A}$ multiservices wireless access for end users, such as centralized network resource management, simplified wireless base station structure, easiness for system maintenance and upgrade, and being transparent to radio interface format, as discussed above $[6,17]$. RoF technique based multiservices wireless access systems are mostly applied for personal mobile communication. Bock et al. [18] have studied the multiplexing of video and data service in the same wireless frequency band and their quality of service (QoS) in an earlier time of this century; Lin et al. [19] have tried to employ QAM-OFDM modulation to transmit multiservices with total data rate at $28 \mathrm{Gbit} / \mathrm{s}$ in $7 \mathrm{GHz}$ license-free wireless band. Consider that RoF technique is transparent to bandwidth as well as radio signal format; Chowdhury et al. [20] have proposed a multiservices RoF system with three different formats of wireless signal including Wireless Fidelity (WiFi), World Interoperability for Microwave Access (WiMAX), and millimeter wave modulated into the same optical carrier so as to realize multiservices transmission; likewise, Yang et al. [21] have proposed an almost the same system with Global System for Mobile (GSM) communication, universal mobile telecommunications service (UMTS), and WiMAX signal integrated in the same optical carrier and have analyzed the interference between different services in different frequency bands via simulation; based on the same kind of concept, Zhang et al. [22] have proposed a $3 \mathrm{M}$ (multiservices, multibands, and multiple input multiple output) modulation concept which is still to load multiservices in different frequency bands onto the optical carrier of RoF system. As for performance analysis of multiservices transmission in RoF system, Rebhi et al. [23] have studied the performance of single side band (SSB) spectrum transmission with three different services in $2.4 \mathrm{GHz}, 5 \mathrm{GHz}$, and $60 \mathrm{GHz}$ bands modulated on optical carrier. Like WDM-PON, RoF technique based multiservices transmission system also requires simplified design so as to save construction cost and to make itself easier to be commercially promoted; Liu et al. [24] have tried to replace RoF base stations by remote antenna units (RAUs) which have simpler structure with only wireless signal relay function in it and have centralized all the base band signal processing into the central stations (CSs); Cheng et al. [25] have employed differentiated phase optical code division multiple access (OCDMA) to do the spectral encoding so as to save system cost in end user identification and routing aspect.

2.3. On System Design of WDM-RoF-PON with Multiservices Integrated. It is of no doubt that by introducing RoF technique in WDM-PON design and thus building 


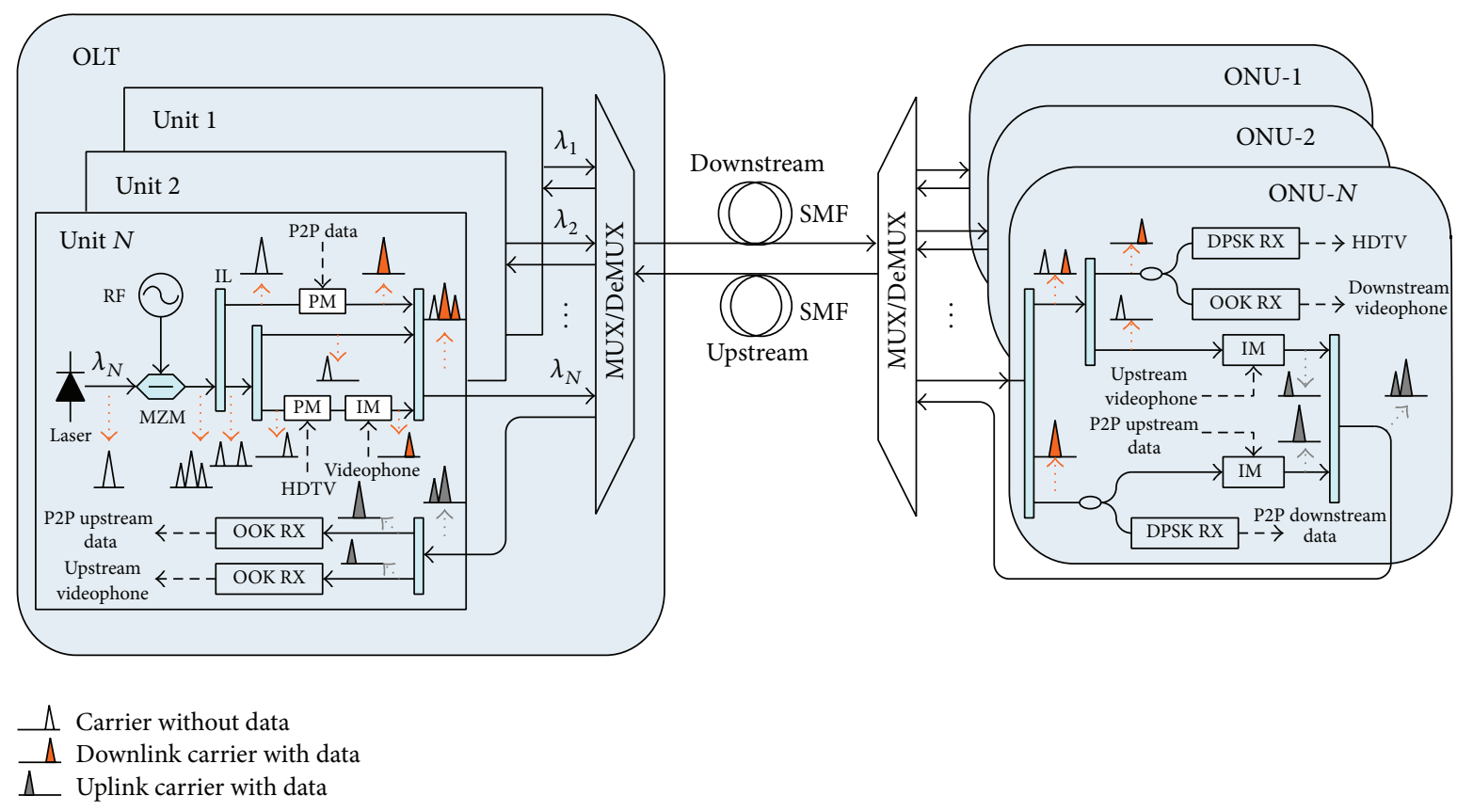

FIGURE 1: System structure of quintuple services integrated WDM-RoF-PON (RX: receiver).

a WDM-RoF-PON system as it has been usually called, both the advantages of RoF technique and WDM-PON system can be utilized properly in the wireless and optical access provided by it. Huge bandwidth resources of WDM-PON can be used to transmit both baseband and wireless broadband services with higher reliability and quality. Before the year of 2000, the thoughts of combination RoF technique and WDM-PON had been proposed by Smith et al. [26], who had pointed out that multiwireless services can be provided by WDM-RoF-PON as well as high rate digital baseband services. Then, for the specific key technologies in WDM-RoFPON, Jia et al. [27] have studied the generation of RoF signal and the wavelength reusing scheme in ONUs. As it comes to the multiservices access of WDM-RoF-PON, Pham et al. [28] have made a structure design with double downstream services including UWB and baseband data transmitting simultaneously; Cao et al. [29] have designed a quadruple services system structure with both wireless and baseband data services transmitted bidirectionally; affected by centralized lightwave concept in WDM-PON system design, Yang et al. [30] have utilized local optical amplifier in ONUs to save construction cost of the system which has almost the same structure as [29]. Later on, more different types of wireless services in different frequency band have been added to WDM-RoFPON structure; in each wavelength channel distributed by WDM-RoF-PON system, Zhu et al. [31] have tried to load three different services in WiFi, WiMAX, and millimeter wave band separately, while Rodrigues et al. [32] have tried to realize the transmission of bidirectional LTE, WiMAX, and UWB services as well as baseband orthogonal frequency division multiplexing (OFDM) signal simultaneously. However, the bandwidth of each wavelength channel in system schemes of literature $[31,32]$ is a bit too wide, and thus the bandwidth efficiency is relatively low. To improve the bandwidth efficiency, the WDM-RoF-PON scheme has been proposed by Nai et al. [8] which can achieve the transmission of quintuple broadband services in lower than $20 \mathrm{GHz}$ bandwidth by jointly employing orthogonal modulation, carrier multiplexing, and remodulation technique in each wavelength channel with simple data modulation formats, can be on some level recognized as the most feasible design to realize multiservices in limited bandwidth, and has already been verified via simulation and experiment; however, mathematical verification of such scheme still remained to be done and that is what exactly this paper aims at.

\section{System Design and Performance Verification}

Here, in this section, the system design of WDM-RoFPON with high bandwidth efficiency in literature [8] will be redescribed firstly, and then its downstream and upstream performance will be analyzed in theory separately.

3.1. Description of System Design. Quintuple services integrated WDM-RoF-PON provides three downstream services including baseband P2P data access, wireless access, and wireless broadcast services and also provides two upstream services including P2P data upload and wireless upload services. The architecture of such WDM-RoF-PON system can be shown in Figure 1. In optical line terminal (OLT) or $\mathrm{CS}$ as it has been sometimes called, external modulators are used in each wavelength channel so as to let a sinusoidal radio frequency $(\mathrm{RF})$ signal modulate the optical source; thus, in the spectrum of modulated signal, the original single peak can be changed as one central peak combined with side bands. 
Keeping the DSB spectrum with only central peak and the first-order side bands, the signal is then separated by two interleavers (ILs) as three parts: the central peak, the firstorder upper side band (USB), and the first-order lower side band (LSB). For the central peak, it has been modulated by a phase modulator (PM) which has an input of $10 \mathrm{Gbit} / \mathrm{s}$ P2P downstream data; thus, a differentiated phase shift keying (DPSK) signal is formed; for the USB, it has also been modulated by a PM which has an input of $1 \mathrm{Gbit} / \mathrm{s}$ wireless downstream data; moreover, it has been then modulated by an intensity modulator (IM) which has an input of $2.5 \mathrm{Gbit} / \mathrm{s}$ wireless broadcast data; thus, in the upper side band (USB), an orthogonally modulated DPSK/on-off keying (OOK) signal is formed; and for the LSB, it has been kept without any data modulated. After the downstream data modulation, these three frequency components are then been combined together by another IL, and the downstream services are modulated onto each wavelength channel properly. Signals in all wavelength channels are then multiplexed by a multiplexer (MUX) and then been sent to downlink single mode fiber (SMF) for transmission.

After transmission, the multiplexed downstream signal is sent to a demultiplexer (DeMUX) which is deployed in optical distribution network (ODN) or remote node (RN) for demultiplexing; signal in each wavelength channel is thus been separated and sent to each corresponding ONU. In each ONU, side bands are separated from the central peak by an IL so as to do the demodulation of wireless downstream data independently; two wireless downstream services can either be acquired in RF form by utilizing frequency beat effect and frequency divider or be acquired in baseband form by demodulating the USB with optical DPSK and OOK receiver. Apart from the side bands of downstream signal, the central peak is also separated by IL and part of its power is sent to optical DPSK receiver for baseband P2P data demodulation. As a matter of fact, remodulation technique is applied in this system structure design. In each wavelength channel, the remaining power of the central peak is reused as optical carrier to modulate $10 \mathrm{Gbit} / \mathrm{s}$ P2P upstream data by using an IM; thus, one OOK upstream signal is formed; and the LSB which is empty during the downlink transmission is then also used as carrier to modulate $1 \mathrm{Gbit} / \mathrm{s}$ wireless upstream signal which is in baseband form by another IM; thus, the other OOK upstream signal is formed. Finally, the remodulated central peak and the LSB are combined together by an IL so as to form a single side band (SSB) signal and then sent to uplink SMF after a proper power matching step has been done. Back to OLT, the only devices required are an IL and two sets of OOK receiver so as to demodulate $\mathrm{P} 2 \mathrm{P}$ and wireless upstream data. Till now, all the process of quintuple services transmission in this system structure has been realized.

3.2. Verification of Downstream Performance. According to the system structure, data of the three downstream services are modulated on different carrier components including central peak and USB and are then multiplexed with LSB so as to form a DSB spectrum. It can be easily inferred that as different services are modulated on carriers with different frequency value, pulse width shifting and distortion of each data symbol, which are caused by fiber dispersion and are the major causes of bit error rate (BER) deterioration, will certainly happen. In this section, system performance of downstream data transmission will be theoretically analyzed on considering the problems mentioned above.

As system design in literature [11], carrier multiplexing of DSB spectrum is usually employed by modulating different service data onto central peak and both the first-order side bands. Suppose that the downstream P2P data sequence which is phase modulated onto the central peak can be described as $a(\varphi)$; the wireless downstream data sequence which is phase modulated onto the USB can be described as $b(\varphi)$, and the broadcast data sequence which is intensity modulated onto the USB can be described as $c(t)$; therefore, the DSB signal with three downstream services modulated by carrier multiplexing can be described as

$$
\begin{aligned}
A(0, t) & \\
= & a_{0} \exp \left\{j\left[2 \pi f_{c} t+a(\varphi)\right]\right\} \\
& +c(t)\left\{a_{-1} \exp \left\{j\left[2 \pi\left(f_{c}+f_{\mathrm{RF}}\right) t+b(\varphi)\right]\right\}\right\} \\
& +c(t)\left\{a_{+1} \exp \left\{j\left[2 \pi\left(f_{c}-f_{\mathrm{RF}}\right) t+b(\varphi)\right]\right\}\right\},
\end{aligned}
$$

where $a_{k}(k=0, \pm 1)$ is the relative magnitude of each frequency component; for DSB spectrum, $a_{0}>a_{-1}=a_{+1}$ is the usual situation. For the convenience of discussion, let $a_{1}=$ $a_{-1}=a_{+1}$; then, the power spectrum density of $A(0, t)$ can be calculated as

$$
\begin{aligned}
P(0, t)= & a_{0}^{2} \delta\left(f-f_{c}\right) \delta\left(-f+f_{c}\right) \\
& +a_{1}^{2} C\left(f-f_{c}+f_{\mathrm{RF}}\right) C\left(-f+f_{c}-f_{\mathrm{RF}}\right) \\
& +a_{1}^{2} C\left(f-f_{c}-f_{\mathrm{RF}}\right) C\left(-f+f_{c}+f_{\mathrm{RF}}\right)
\end{aligned}
$$

where $\delta(f)$ is the unit impulse function and $C(f)$ is the Fourier transform of $c(t)$. It can be easily seen that the spectrum width of DSB signal is $2 f_{\mathrm{RF}}$. If the signal has been experiencing only a back to back (B2B) transmission, namely, the signal is received abruptly after it has been transmitted without being sent into the fiber link, then the signal received can be written as

$$
\begin{aligned}
A_{r}(0, t) \\
=\eta\left[a_{0}^{2}+2 c^{2}(t) a_{1}^{2}\right] \\
\quad+\eta c(t)\left\{4 a_{0} a_{1} \cos [a(\varphi)-b(\varphi)] \cos 2 \pi f_{\mathrm{RF}} t\right\} \\
\quad+\eta c^{2}(t)\left[2 a_{1}^{2} \cos 2\left(2 \pi f_{\mathrm{RF}} t\right)\right]
\end{aligned}
$$

where $\eta$ is the attenuation coefficient of amplitude. It can be found that the received DSB signal with three downstream services integrated mainly consisted of main carrier and 
the first-order RF harmonic. If the DSB signal has been transmitted for $z \mathrm{~km}$ in the downlink fiber, as it would be affected by the dispersion effect, the received signal can be written as

$$
\begin{aligned}
& A(z, t)=a_{1} \cdot c\left[t-\frac{\beta\left(f_{c}-f_{\mathrm{RF}}\right)}{2 \pi\left(f_{c}-f_{\mathrm{RF}}\right)} z\right] \\
& \cdot \exp \left\{j\left[2 \pi\left(f_{c}-f_{\mathrm{RF}}\right) t+\beta\left(f_{c}-f_{\mathrm{RF}}\right) z+b(\varphi)\right]\right. \\
& \quad-\gamma z\}+a_{1} \cdot c\left[t-\frac{\beta\left(f_{c}+f_{\mathrm{RF}}\right)}{2 \pi\left(f_{c}+f_{\mathrm{RF}}\right)} z\right] \\
& \cdot \exp \left\{j\left[2 \pi\left(f_{c}+f_{\mathrm{RF}}\right) t+\beta\left(f_{c}+f_{\mathrm{RF}}\right) z+b(\varphi)\right]\right. \\
& \quad-\gamma z\}+a_{0} \cdot \exp \left\{j\left[2 \pi f_{c} t+a(\varphi)\right]-\gamma z\right\},
\end{aligned}
$$

where $\beta(f)$ is the zero-order coefficient value of Taylor expansion in frequency point $f$ of the transmission function affected by the fiber dispersion coefficient. The power spectrum density of (4) can be calculated as

$$
\begin{gathered}
P(z, t)=\exp (-N z)\left[a_{0}^{2} \delta\left(f-f_{c}\right) \delta\left(-f+f_{c}\right)\right. \\
+a_{1}^{2} C\left(f-f_{c}+f_{\mathrm{RF}}\right) C\left(-f+f_{c}-f_{\mathrm{RF}}\right) \\
\left.+a_{1}^{2} C\left(f-f_{c}-f_{\mathrm{RF}}\right) C\left(-f+f_{c}+f_{\mathrm{RF}}\right)\right] .
\end{gathered}
$$

It is easy to be seen that the power spectrum density $P(z, t)$ of the DSB signal after transmission for $z \mathrm{~km}$ is almost the same apart from a loss value $\exp (-N z)$; namely, the optical spectrum has not been changed in the $z \mathrm{~km}$ transmission. However, the signal inside the spectrum has been violently changed; for the convenience of discussion, let

$$
\begin{aligned}
& C_{-1}=c\left[t-\frac{\beta\left(f_{c}-f_{\mathrm{RF}}\right)}{2 \pi\left(f_{c}-f_{\mathrm{RF}}\right)} z\right], \\
& C_{+1}=c\left[t-\frac{\beta\left(f_{c}+f_{\mathrm{RF}}\right)}{2 \pi\left(f_{c}+f_{\mathrm{RF}}\right)} z\right] .
\end{aligned}
$$

Then, the received signal of photo detector with central frequency at $f_{c}$ is

$$
\begin{aligned}
& A_{r}(z, t)=\eta\left(a_{0}^{2}+a_{1}^{2} C_{-1}^{2}+a_{1}^{2} C_{+1}^{2}\right)+2 \eta a_{0} a_{1} C_{-1} \\
& \cdot \cos \left[2 \pi f_{\mathrm{RF}} t+\beta\left(f_{c}-f_{\mathrm{RF}}\right) z-\beta\left(f_{c}\right) z+a(\varphi)\right. \\
& \quad-b(\varphi)]+2 \eta a_{0} a_{1} C_{+1} \cdot \cos \left[2 \pi f_{\mathrm{RF}} t+\beta\left(f_{c}\right) z\right. \\
& \left.\quad-\beta\left(f_{c}+f_{\mathrm{RF}}\right) z+a(\varphi)-b(\varphi)\right]+2 \eta a_{1}^{2} C_{-1} C_{+1} \\
& \quad \cdot \cos \left[2\left(2 \pi f_{\mathrm{RF}}\right) t+\beta\left(f_{c}-f_{\mathrm{RF}}\right) z-\beta\left(f_{c}+f_{\mathrm{RF}}\right) z\right] .
\end{aligned}
$$

By employing transformation of trigonometric function and doing the expansion of $\beta(f)$ in $f=f_{c}$, (7) can then be written as

$$
\begin{aligned}
& A_{r}(z, t)=\eta\left(a_{0}^{2}+a_{1}^{2} C_{-1}^{2}+a_{1}^{2} C_{+1}^{2}\right) \\
& +2 \eta a_{0} a_{1}\left(C_{+1}+C_{-1}\right) \cdot \cos 2 \pi f_{\mathrm{RF}}\left[t+\beta^{\prime}\left(f_{c}\right) z\right] \\
& \quad \cdot \cos \left[\frac{1}{2}\left(2 \pi f_{\mathrm{RF}}\right)^{2} \beta^{\prime \prime}\left(f_{c}\right) z+a(\varphi)-b(\varphi)\right] \\
& \quad+2 \eta a_{0} a_{1}\left(C_{+1}-C_{-1}\right) \cdot \cos 2 \pi f_{\mathrm{RF}}\left[t+\beta^{\prime}\left(f_{c}\right) z\right] \\
& \quad \cdot \sin \left[\frac{1}{2}\left(2 \pi f_{\mathrm{RF}}\right)^{2} \beta^{\prime \prime}\left(f_{c}\right) z+a(\varphi)-b(\varphi)\right] .
\end{aligned}
$$

Comparing (8) with (3), the two DPSK downstream signals have not been affected by fiber dispersion so much; however, the OOK signal on side bands has been affected by the different transmission velocities of different frequency components, and its pulse width will be shifted gradually in time domain. From (8), the shifting of $C_{-1}$ and $C_{+1}$ will strongly affect the performance of the OOK signal, for different value of $\left(C_{-1}+C_{-1}\right)$ and $\left(C_{-1}-C_{-1}\right)$ will change the sensitivity of signal demodulation.

The modulation of downstream services in the system design in this paper is different from the traditional way; data of two broadband downstream services have been only modulated on the USB of the DSB spectrum; different from (1), the DSB signal after modulation can be written as

$$
\begin{aligned}
A(0, t) & \\
= & a_{0} \exp \left\{j\left[2 \pi f_{c} t+a(\varphi)\right]\right\} \\
& +c(t)\left\{a_{-1} \exp \left\{j\left[2 \pi\left(f_{c}+f_{\mathrm{RF}}\right) t+b(\varphi)\right]\right\}\right\} \\
& +c(t)\left\{a_{+1} \exp \left[j 2 \pi\left(f_{c}-f_{\mathrm{RF}}\right) t\right]\right\} .
\end{aligned}
$$

And the corresponding power spectrum density is

$$
\begin{aligned}
P(0, t)= & a_{0}^{2} \delta\left(f-f_{c}\right) \delta\left(-f+f_{c}\right) \\
& +a_{1}^{2} C\left(f-f_{c}-f_{\mathrm{RF}}\right) C\left(-f+f_{c}+f_{\mathrm{RF}}\right) \\
& +a_{1}^{2} \delta\left(f-f_{c}+f_{\mathrm{RF}}\right) \delta\left(-f+f_{c}-f_{\mathrm{RF}}\right) .
\end{aligned}
$$

After transmission for $z \mathrm{~km}$ and being affected by fiber dispersion effect, the DSB signal with three downstream services integrated can be written as

$$
\begin{aligned}
& A(z, t)=a_{1} \cdot c\left[t-\frac{\beta\left(f_{c}+f_{\mathrm{RF}}\right)}{2 \pi\left(f_{c}+f_{\mathrm{RF}}\right)} z\right] \\
& \quad \cdot \exp \left\{j\left[2 \pi\left(f_{c}+f_{\mathrm{RF}}\right) t+\beta\left(f_{c}+f_{\mathrm{RF}}\right) z+b(\varphi)\right]\right. \\
& \quad-\gamma z\}+a_{1} \\
& \quad \cdot \exp \left\{j\left[2 \pi\left(f_{c}-f_{\mathrm{RF}}\right) t+\beta\left(f_{c}-f_{\mathrm{RF}}\right) z\right]-\gamma z\right\} \\
& \quad+a_{0} \cdot \exp \left\{j\left[2 \pi f_{c} t+a(\varphi)\right]-\gamma z\right\} .
\end{aligned}
$$


And the corresponding power spectrum density is

$$
\begin{gathered}
P(z, t)=\exp (-N z)\left[a_{0}^{2} \delta\left(f-f_{c}\right) \delta\left(-f+f_{c}\right)\right. \\
+a_{1}^{2} C\left(f-f_{c}-f_{\mathrm{RF}}\right) C\left(-f+f_{c}+f_{\mathrm{RF}}\right) \\
\left.+a_{1}^{2} \delta\left(f-f_{c}+f_{\mathrm{RF}}\right) \delta\left(-f+f_{c}-f_{\mathrm{RF}}\right)\right] .
\end{gathered}
$$

The same as the traditional modulation of service data onto DSB spectrum, the power spectrum density $P(z, t)$ of the DSB signal after transmission for $z \mathrm{~km}$ is almost the same apart from a loss value $\exp (-N z)$; in this situation, the received signal of photo detector with central frequency at $f_{c}$ is

$$
\begin{aligned}
& A_{r}(z, t)=\eta\left(a_{0}^{2}+a_{1}^{2} C_{+1}^{2}+a_{1}^{2}\right)+2 \eta a_{0} a_{1} \cdot \cos \left[2 \pi f_{\mathrm{RF}} t\right. \\
& \left.\quad+\beta\left(f_{c}-f_{\mathrm{RF}}\right) z-\beta\left(f_{c}\right) z+a(\varphi)-\frac{1}{2} b(\varphi)\right] \\
& \quad+2 \eta a_{0} a_{1} C_{+1} \cdot \cos \left[2 \pi f_{\mathrm{RF}} t+\beta\left(f_{c}\right) z\right. \\
& \left.\quad-\beta\left(f_{c}+f_{\mathrm{RF}}\right) z+a(\varphi)-\frac{1}{2} b(\varphi)\right]+2 \eta a_{1}^{2} C_{+1} \\
& \quad \cdot \cos \left[2\left(2 \pi f_{\mathrm{RF}}\right) t+\beta\left(f_{c}-f_{\mathrm{RF}}\right) z-\beta\left(f_{c}+f_{\mathrm{RF}}\right) z\right] .
\end{aligned}
$$

By employing transformation of trigonometric function, and doing the expansion of $\beta(f)$ in $f=f_{c}$, (13) can then be written as

$$
\begin{aligned}
& A_{r}(z, t)=\eta\left(a_{0}^{2}+a_{1}^{2} C_{+1}^{2}+a_{1}^{2}\right)+2 \eta a_{0} a_{1}\left(C_{+1}+1\right) \\
& \cdot \cos 2 \pi f_{\mathrm{RF}}\left[t+\beta^{\prime}\left(f_{c}\right) z\right] \\
& \cdot \cos \left[\frac{1}{2}\left(2 \pi f_{\mathrm{RF}}\right)^{2} \beta^{\prime \prime}\left(f_{c}\right) z+a(\varphi)-\frac{1}{2} b(\varphi)\right] \\
& +2 \eta a_{0} a_{1}\left(C_{+1}-1\right) \cdot \cos 2 \pi f_{\mathrm{RF}}\left[t+\beta^{\prime}\left(f_{c}\right) z\right] \\
& \cdot \sin \left[\frac{1}{2}\left(2 \pi f_{\mathrm{RF}}\right)^{2} \beta^{\prime \prime}\left(f_{c}\right) z+a(\varphi)-\frac{1}{2} b(\varphi)\right] .
\end{aligned}
$$

By comparing (8) and (14), it can be easily seen that as no service data has been modulated onto LSB of the DSB spectrum, no overlapping of $C_{-1}$ and $C_{+1}$ will happen; therefore, the sensitivity of OOK data demodulation will not be affected by pulse width shifting any more, and the limitation of transmission distance caused by pulse width shifting of traditional service data modulation in DSB spectrum can thus be solved.

3.3. Verification of Upstream Performance. According to the system structure, data of two upstream services are modulated on part of the power of downstream central peak and LSB which has not been utilized as carrier in the transmission of downstream data; therefore, a SSB spectrum has been formed then. In this section, system performance of upstream data transmission will be theoretically analyzed.

Suppose that power matching has already been done before the upstream SSB signal is sent to the uplink; the USB has been fully filtered out, and suppose that the upstream signal will not be affected by downstream signal; if the upstream
P2P data sequence which is intensity remodulated onto the central peak is described as $a(t)$, the wireless upstream data sequence which is intensity remodulated onto the LSB can be described as $b(t)$; then, the SSB signal with two upstream services modulated by carrier multiplexing can be described as

$$
\begin{aligned}
& A(0, t) \\
& =a(t)\left\{a_{0} \exp \left[j\left(2 \pi f_{c} t+\varphi_{0}\right)\right]\right\} \\
& +b(t)\left\{a_{-1} \exp \left\{j\left[2 \pi\left(f_{c}-f_{\mathrm{RF}}\right) t+\varphi_{-1}\right]\right\}\right\} .
\end{aligned}
$$

Still, $a_{k}(k=0,-1)$ is the relative magnitude of each frequency component; for the SSB spectrum which has experienced power matching, $a_{0}>a_{-1}$ is the usual situation. For the convenience of discussion, let $a_{1}=a_{-1}$; then, the power spectrum density of $A(0, t)$ can be calculated as

$$
\begin{aligned}
P(0, t)= & a_{0}^{2} A\left(f-f_{c}\right) A\left(-f+f_{c}\right) \\
& +a_{1}^{2} B\left(f-f_{c}+f_{\mathrm{RF}}\right) B\left(-f+f_{c}-f_{\mathrm{RF}}\right),
\end{aligned}
$$

where $A(f)$ and $B(f)$ are the Fourier transforms of $a(t)$ and $b(t)$, respectively. It can be seen that the spectrum width of upstream SSB signal is $f_{\mathrm{RF}}$. If the signal has been experiencing only a $\mathrm{B} 2 \mathrm{~B}$ transmission, then the signal received can be written as

$$
\begin{aligned}
A_{r}(0, t) & \\
=\eta & {\left[a^{2}(t) a_{0}^{2}+b^{2}(t) a_{1}^{2}\right]+\eta } \\
& \cdot a(t) b(t)\left[2 a_{0} a_{1} \cos \left(\varphi_{0}-\varphi_{1}\right) \cos 2 \pi f_{\mathrm{RF}} t\right] .
\end{aligned}
$$

It can be found that the received SSB signal with two upstream services integrated mainly consisted of main carrier and the first-order RF harmonic. If the SSB signal has been transmitted for $z \mathrm{~km}$ in the uplink fiber, as it would be affected by the dispersion effect, the received signal can be written as

$$
\begin{aligned}
& A(z, t)=a_{1} \cdot b\left[t-\frac{\beta\left(f_{c}-f_{\mathrm{RF}}\right)}{2 \pi\left(f_{c}-f_{\mathrm{RF}}\right)} z\right] \\
& \cdot \exp \left\{j\left[2 \pi\left(f_{c}-f_{\mathrm{RF}}\right) t+\beta\left(f_{c}-f_{\mathrm{RF}}\right) z+\varphi_{1}\right]\right. \\
& \quad-\gamma z\}+a_{0} \cdot a\left[t-\frac{\beta\left(f_{c}\right)}{2 \pi f_{c}} z\right] \exp \left\{j\left[2 \pi f_{c} t+\varphi_{0}\right]\right. \\
& -\gamma z\},
\end{aligned}
$$

where $\beta(f)$ is the zero-order coefficient value of Taylor expansion in frequency point $f$ of the transmission function affected by the fiber dispersion coefficient. The power spectrum density of (18) can be calculated as

$$
\begin{gathered}
P(z, t)=\exp (-N z)\left[a_{0}^{2} A\left(f-f_{c}\right) A\left(-f+f_{c}\right)\right. \\
\left.+a_{1}^{2} B\left(f-f_{c}+f_{\mathrm{RF}}\right) B\left(-f+f_{c}-f_{\mathrm{RF}}\right)\right] .
\end{gathered}
$$

It is easy to be seen that the power spectrum density $P(z, t)$ of the SSB signal after transmission for $z \mathrm{~km}$ is almost 
the same apart from a loss value $\exp (-N z)$, namely, the optical spectrum has not been changed in the $z \mathrm{~km}$ transmission. However, pulse width shifting in its corresponding time domain has been already taking place. For the convenience of analyzing such issue, let

$$
\begin{aligned}
A & =a\left[t-\frac{\beta\left(f_{c}\right)}{2 \pi f_{c}} z\right], \\
B_{-1} & =b\left[t-\frac{\beta\left(f_{c}-f_{\mathrm{RF}}\right)}{2 \pi\left(f_{c}-f_{\mathrm{RF}}\right)} z\right] .
\end{aligned}
$$

Then, the received signal of photo detector with central frequency at $f_{c}$ is

$$
\begin{aligned}
& A_{r}(z, t)=\eta\left(a_{0}^{2} A^{2}+a_{1}^{2} B_{-1}^{2}\right)+2 \eta a_{0} a_{1} A B_{-1} \\
& \quad \cdot \cos \left[2 \pi f_{\mathrm{RF}} t+\beta\left(f_{c}-f_{\mathrm{RF}}\right) z-\beta\left(f_{c}\right) z+\varphi_{0}-\varphi_{1}\right] .
\end{aligned}
$$

By comparing (21) and (17), it can be seen that as there is difference in frequency value between main carrier and LSB, pulse width shifting caused by the difference in transmission velocity between main carrier and LSB will surely take place. In order to analyze this issue in detail, the transformation form of (21) can be done by employing transformation of trigonometric function, and by doing the expansion of $\beta(f)$ in $f=f_{c}$, and can then be written as

$$
\begin{aligned}
& A_{r}(z, t)=\eta\left(a_{0}^{2} A^{2}+a_{1}^{2} B_{-1}^{2}\right)+2 \eta a_{0} a_{1} A B_{-1} \cos 2 \pi f_{\mathrm{RF}} \\
& \cdot\left[t+\beta^{\prime}\left(f_{c}\right) z\right] \\
& \cdot \cos \left[\frac{1}{2}\left(2 \pi f_{\mathrm{RF}}\right)^{2} \beta^{\prime \prime}\left(f_{c}\right) z+\varphi_{0}-\varphi_{1}\right] \\
& +2 \eta a_{0} a_{1} A B_{-1} \sin 2 \pi f_{\mathrm{RF}}\left[t+\beta^{\prime}\left(f_{c}\right) z\right] \\
& \cdot \sin \left[\frac{1}{2}\left(2 \pi f_{\mathrm{RF}}\right)^{2} \beta^{\prime \prime}\left(f_{c}\right) z+\varphi_{0}-\varphi_{1}\right] .
\end{aligned}
$$

As both two upstream services have employed OOK modulation in system structure design, then the demodulation sensitivity will be affected by item $A B_{-1}$, which is directly affected by the shifting between main carrier and LSB. Therefore, the transmission performance should be further analyzed. It is for sure that the time of pulse width shifting depends on the data rate $R$ of the two upstream services; the pulse will be fully shifted when certain pulse is delayed for one bit slot long. To be specific, for the uplink transmission of SSB signal, the relationship between pulse width shifting and the transmission distance $z$ can be written as

$$
\frac{1}{R}=\frac{1}{2 \pi}\left[\frac{\beta\left(f_{c}-f_{\mathrm{RF}}\right)}{f_{c}-f_{\mathrm{RF}}}-\frac{\beta\left(f_{c}\right)}{f_{c}}\right] z .
$$

By doing the Taylor expansion of the transmission function in the right side of (23) in $f=f_{c}$, taking only the first and the second derivative terms, and considering that $f_{c} \gg f_{\mathrm{RF}}$, then (23) can be solved as

$$
z=\frac{1}{R\left(2 \pi f_{\mathrm{RF}}\right) \beta^{\prime \prime}\left(f_{c}\right)}=\frac{c}{R \lambda_{c}^{2} D f_{\mathrm{RF}}} .
$$

It is easy to be calculated that, for $10 \mathrm{Gbit} / \mathrm{s}$ P2P upstream service data, it would take about a $60 \mathrm{~km}$ transmission distance to make its OOK pulse be fully shifted for one bit slot; and for $1 \mathrm{Gbit} / \mathrm{s}$ wireless upstream service data, it would take about $600 \mathrm{~km}$ to fully shift the OOK pulse. Consider that the transmission link distance of business-oriented WDMRoF-PON is usually no longer than $20 \mathrm{~km}$, for the optical bandwidth resource managed by each OLT is limited in each subarea of the whole PON network; therefore, the original OOK signal can on some level be recovered as most part of the original data has not been interfered by its neighbor bit slots; the BER of its demodulation can be controllable. Till now, the feasibility of quintuple services integrated WDM-RoF-PON is verified in theory.

\section{Experiment Duplication}

Here, in this section, experiment system will be duplicated and set up according to the structure design of WDM-RoFPON in the last section as well as in literature [8]; moreover, as a complimentary part of the mathematical verification for system performance, experimental analysis for each data service integrated in this system will also be redone in detail.

4.1. Experiment Setup. The experiment system is set up as Figure 2 shows. In OLT, a distributed feedback (DFB) laser with central wavelength at $1552.52 \mathrm{~nm}$ has been deployed as the optical source in the wavelength channel that, in analysis, a Mach-Zehnder modulator (MZM) modulated by a $20 \mathrm{GHz}$ sinusoidal RF signal input is also deployed so as to generate side bands for wireless service data modulation, and the carrier suppression ratio set by MZM is $12 \mathrm{~dB}$; thus, the power of side bands can be controlled. After three frequency components have been separated by ILs, the main carrier is modulated by another MZM which is driven by $10 \mathrm{Gbit} / \mathrm{s}$ pseudorandom bit sequence (PRBS) with the length $2^{31}-1$ to do phase modulation so as to simulate DPSK P2P downstream service experimentally; the USB is modulated by a set of cascaded MZM and IM which are driven by $2.5 \mathrm{Gbit} / \mathrm{s}$ PRBS with the length $2^{23}-1$ to do phase modulation and $1 \mathrm{Gbit} / \mathrm{s}$ PRBS with the length $2^{19}-1$ to do intensity modulation separately, so as to simulate DPSK/OOK orthogonally modulated broadcast service and wireless downstream service, while the LSB is kept empty. It should be pointed out that, in order to ensure the transmission performance of both two data services which are modulated on USB, the extinction ratio of IM to realize OOK modulation is set at $3 \mathrm{~dB}$. Then, the main carrier, USB, and the empty LSB are multiplexed together by IL as a whole DSB signal in certain wavelength channel with three downstream services integrated and sent into the downlink fiber.

The transmission link is formed by two $20 \mathrm{~km} \mathrm{SMFs,} \mathrm{with}$ both of their dispersion coefficient at $16.5 \mathrm{ps} /(\mathrm{nm} \cdot \mathrm{km})$ and dispersion slope at $0.08 \mathrm{ps} /\left(\mathrm{nm}^{2} \cdot \mathrm{km}\right)$. After transmission, in corresponding $\mathrm{ONU}$ of this very wavelength channel, all the frequency components are separated again by ILs for demodulation and frequency source reuse. The main carrier is further separated by a $3 \mathrm{~dB}$ optical coupler into two parts for DPSK differentially coherent demodulation and OOK 


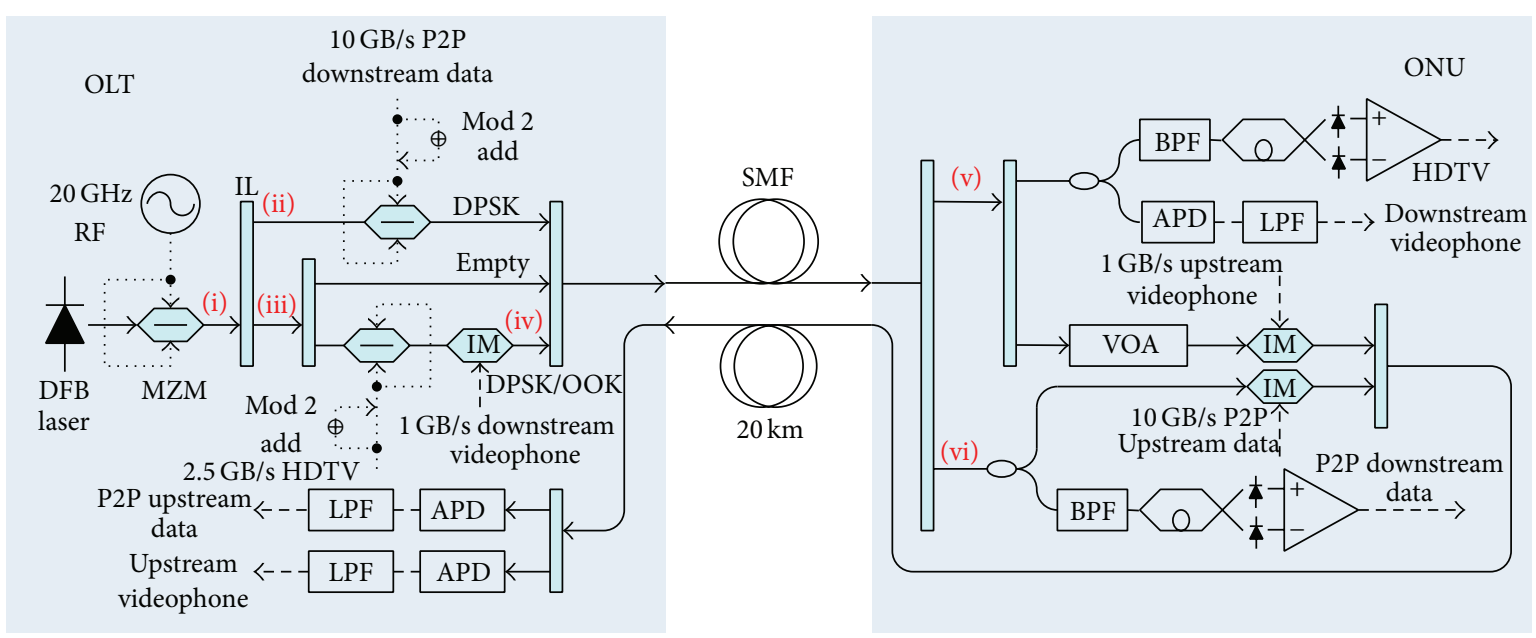

FIGURE 2: Experiment duplication setup of the WDM-RoF-PON system in analysis.

remodulation separately; the latter part is modulated by an IM which is driven by $10 \mathrm{Gbit} / \mathrm{s}$ PRBS with the length $2^{23}-1$ to do intensity modulation so as to simulate OOK P2P upstream service experimentally; the USB part is also further separated by a $3 \mathrm{~dB}$ optical coupler into two parts for DPSK differentially coherent demodulation and OOK demodulation separately; to be specific, the OOK demodulation is combined by a $5 \mathrm{GHz}$ commercial avalanche photo diode (APD) and a low pass filter (LPF), while the LSB part, which is without any data modulated during the transmission in downlink, is then modulated by another IM which is driven by $1 \mathrm{Gbit} / \mathrm{s}$ PRBS with the length $2^{17}-1$ to do intensity modulation so as to simulate OOK wireless upstream service experimentally. In order to eliminate the interference from the downlink data modulated onto the reused spectrum to the greatest extent, the extinction ratios of both two upstream OOK signals are set around $18 \mathrm{~dB}$ according to related research [14]. Moreover, for the LSB with OOK services modulated, a variable optical attenuator (VOA) is deployed to adjust its power so as to realize power matching between the main carrier with remodulated OOK data and the LSB itself, and the carrier suppression ratio is also set at $12 \mathrm{~dB}$ as the downstream DSB spectrum. Back to the OLT, both upstream OOK signals are sent into OOK demodulation module combined with APD and LPF for demodulation.

4.2. Performance Analysis. The optical spectrums for each step in the duplicated experiment system which has been shown in Figure 2 are observed as Figures 3(a)-3(f) show. It can be seen that, in the experiment system, all the spectrum components are properly operated in the certain wavelength channel in both OLT and ONU of such experiment system.

For the three downstream services, their transmission performance measured in the form of BER curves is shown in Figures 4(a) and 4(b). It can be seen from the figure that, under the condition that no signal amplifier or dispersion compensation has been introduced in the experiment system, the receiving sensibility of all these three services are below $-16 \mathrm{dBm}$ when the goal of BER $=10^{-9}$ is achieved. To be specific, after transmission for $20 \mathrm{~km}$, the sensibility of P2P downstream service data which is modulated on the main carrier is $-18.8 \mathrm{dBm}$, which is $0.7 \mathrm{~dB}$ lower than the $\mathrm{B} 2 \mathrm{~B}$ transmission situation; the sensibilities of broadcast service data and wireless downstream service data which are orthogonally modulated on the USB are $-18.7 \mathrm{dBm}$ and $-16.1 \mathrm{dBm}$, which are both $1.2 \mathrm{~dB}$ lower than the $\mathrm{B} 2 \mathrm{~B}$ transmission situation. The transmission performance of all these three services is almost the same as the original experiment work given in literature [8], and the result verifies the mathematical discussion done in the last section of this paper.

For the two upstream services, the measured BER curves are shown in Figures 5(a) and 5(b). It can be seen from the figure that, under the condition that no signal amplifier or dispersion compensation has been introduced in the experiment system, the receiving sensibility of both services are below $-15 \mathrm{dBm}$ when the goal of $\mathrm{BER}=10^{-9}$ is achieved. To be specific, after transmission for $20 \mathrm{~km}$ in the uplink, the sensibility of P2P upstream service data which is modulated on the main carrier is $-16.3 \mathrm{dBm}$, which is $0.7 \mathrm{~dB}$ lower than the $\mathrm{B} 2 \mathrm{~B}$ transmission situation; the sensibility of wireless upstream service data which is modulated on the LSB is $-15.3 \mathrm{dBm}$, which is $1.2 \mathrm{~dB}$ lower than the $\mathrm{B} 2 \mathrm{~B}$ transmission situation. It is easy to notice that the transmission performance of both services is almost the same as the original experiment work given in literature [8], and the result verifies the mathematical discussion done in the last section of this paper.

To deeply analyze Figures 4 and 5, it can be seen that as carrier multiplexing technique has been adopted in both downstream and upstream services, the power difference between main carrier and side bands is as large as the carrier suppression ratio; therefore, the main carrier of the upstream signal received in OLT is $12 \mathrm{~dB}$ larger than the LSB and is about $-3 \mathrm{dBm}$ when both upstream services have reached $10^{-9}$ BER; consider that the fiber loss around wavelength $1550 \mathrm{~nm}$ is about $0.2 \mathrm{~dB} / \mathrm{km}$; the main carrier of the downstream received in each ONU should be larger than $4 \mathrm{dBm}$, which means that, in order to realize quintuple services integrated WDM-RoF-PON, $10 \mathrm{dBm}$ (namely, $10 \mathrm{~mW}$ ) of 


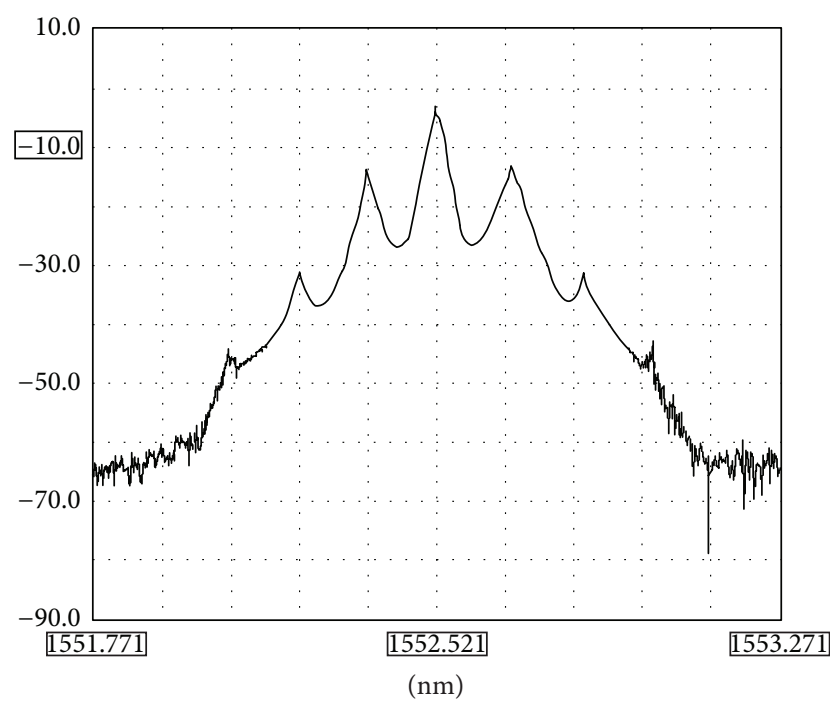

(a)

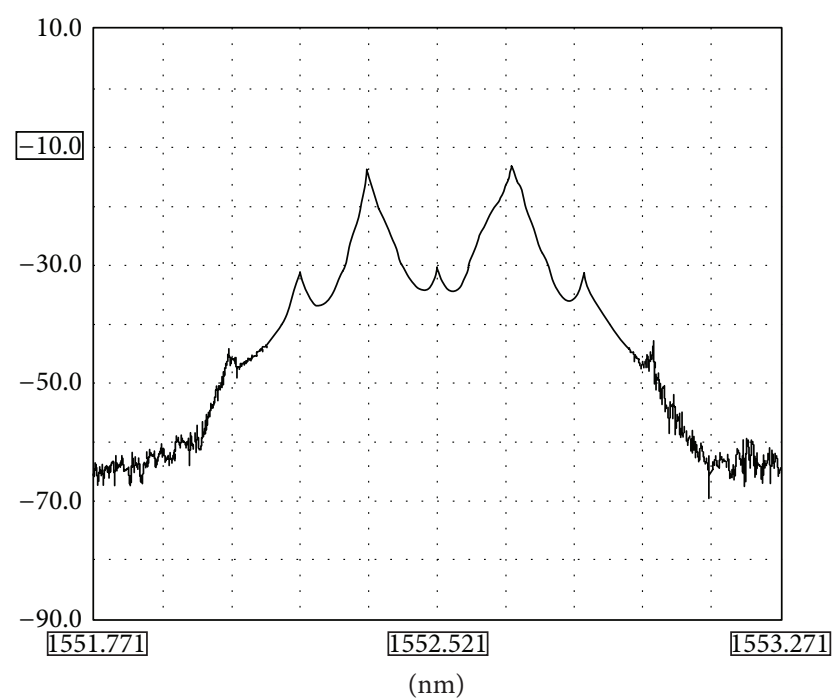

(c)

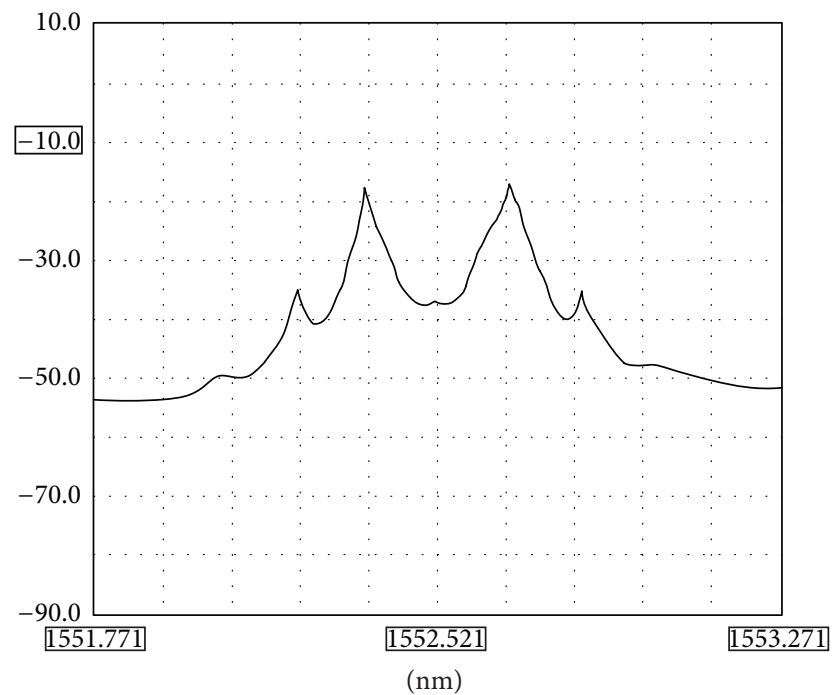

(e)

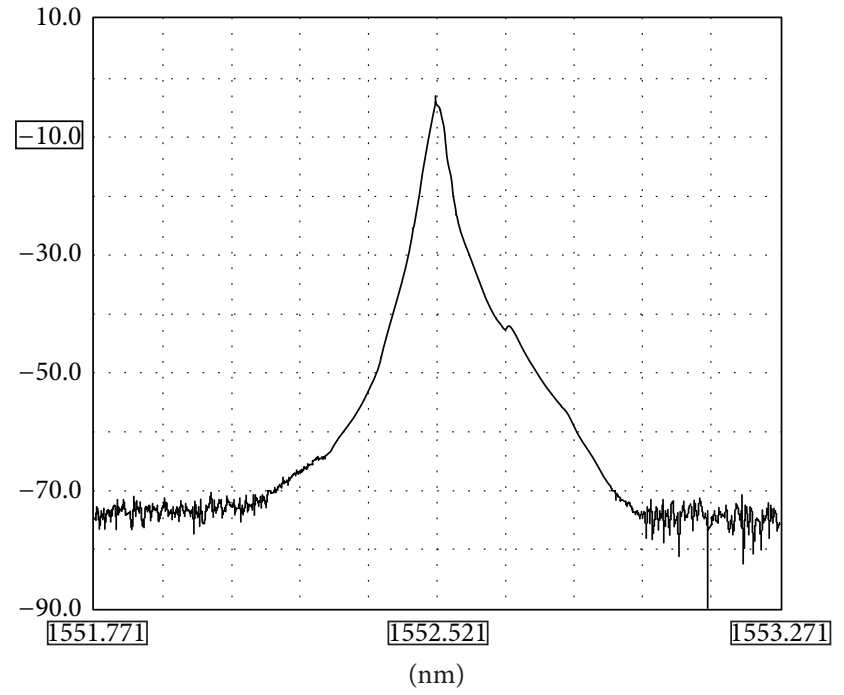

(b)

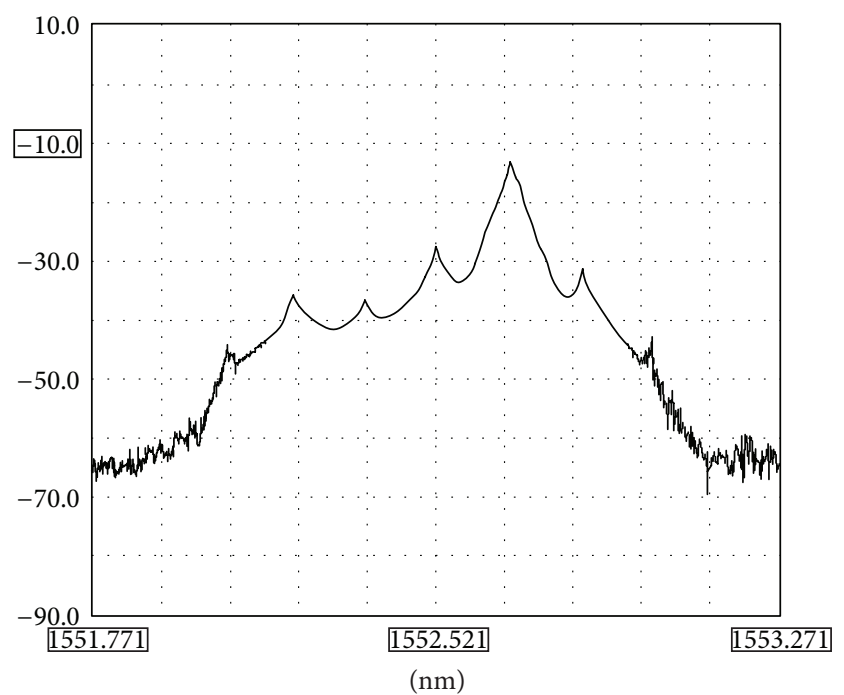

(d)

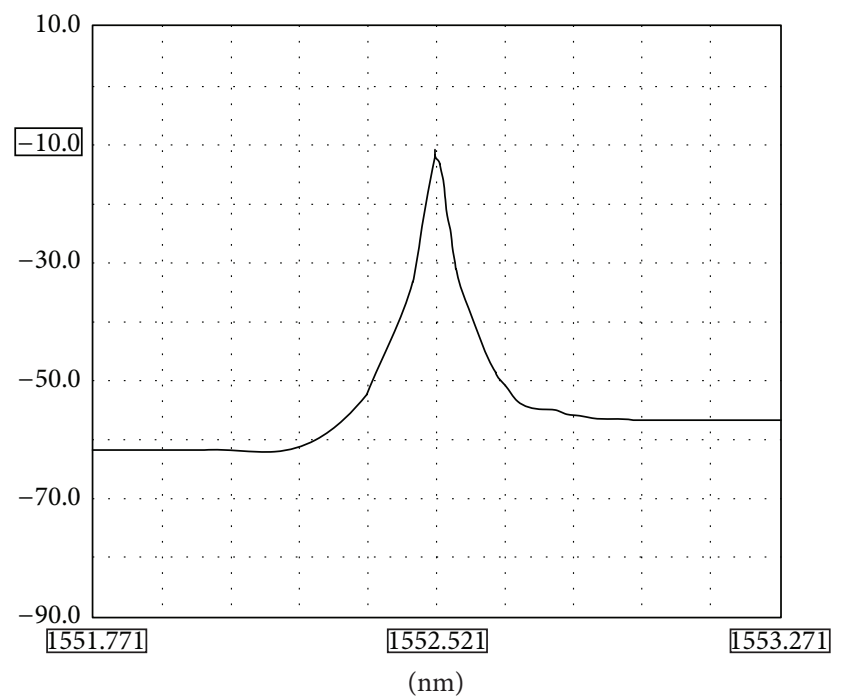

(f)

FIGURE 3: Optical spectrum of all steps in the experiment system [8]. 


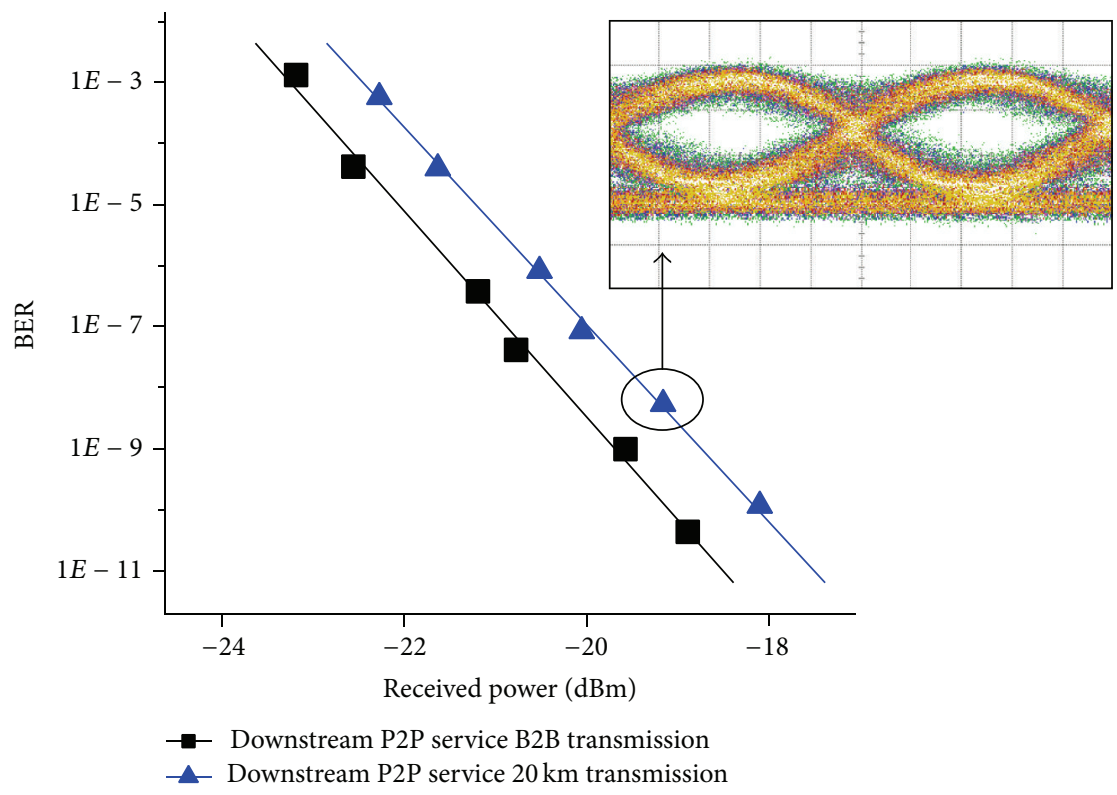

(a)

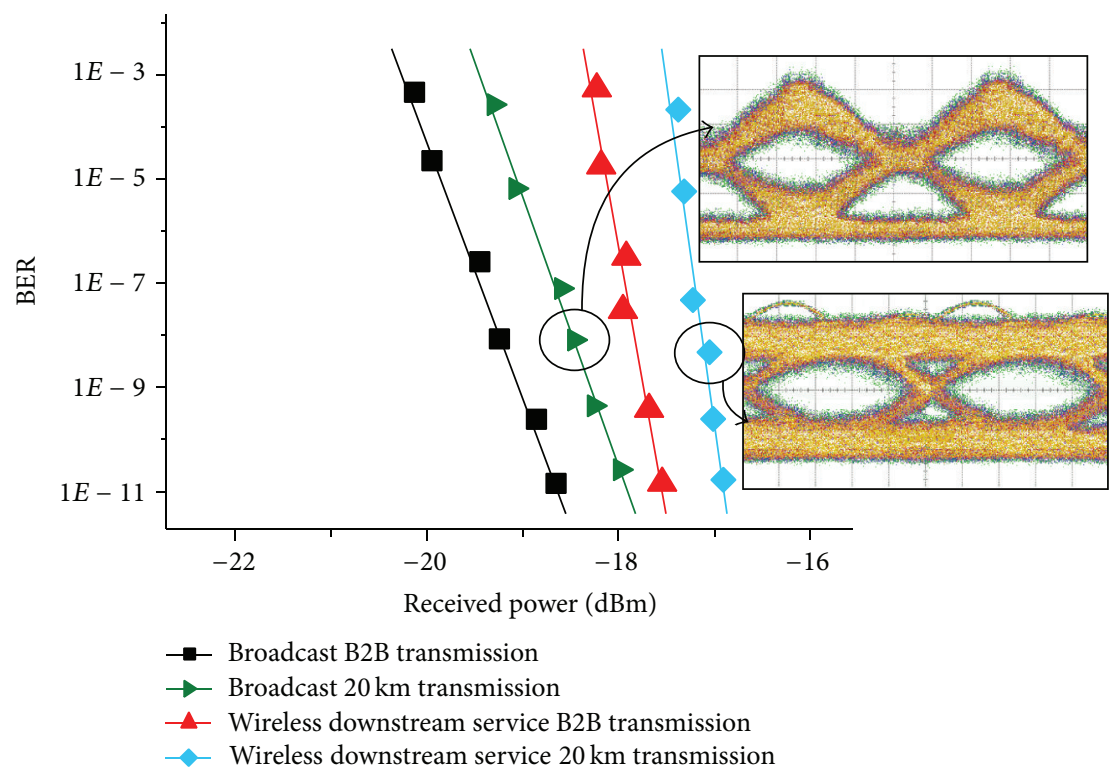

(b)

Figure 4: BER curves and eye diagrams of the three downstream services [8].

the transmission power for the light source in each wavelength channel is fairly enough, and the total power consumption of such system would not be quite large.

\section{Conclusion}

In this paper, mathematical verification has been done for quintuple services integrated WDM-RoF-PON which jointly employs carrier multiplexing technique, orthogonal modulation technique, and remodulation technique in the optical spectrum in each wavelength channel, and experiment duplication for such system has also been done to further verify the theoretical deduction which is the primary contribution of this paper. By theoretically and experimentally giving the results which has shown the effectiveness of such WDM-RoF-PON system design, the theory system of this fiber-wireless access integrated, low energy consumption, and simple signal modulation realization PON has thus been formed. The results shown in this paper would provide meaningful theory references for the construction of access network which integrates functions of both wireless and fiber access and would play an active role in improving multiservices access for WDM-RoF-PON which has huge bandwidth resource. 


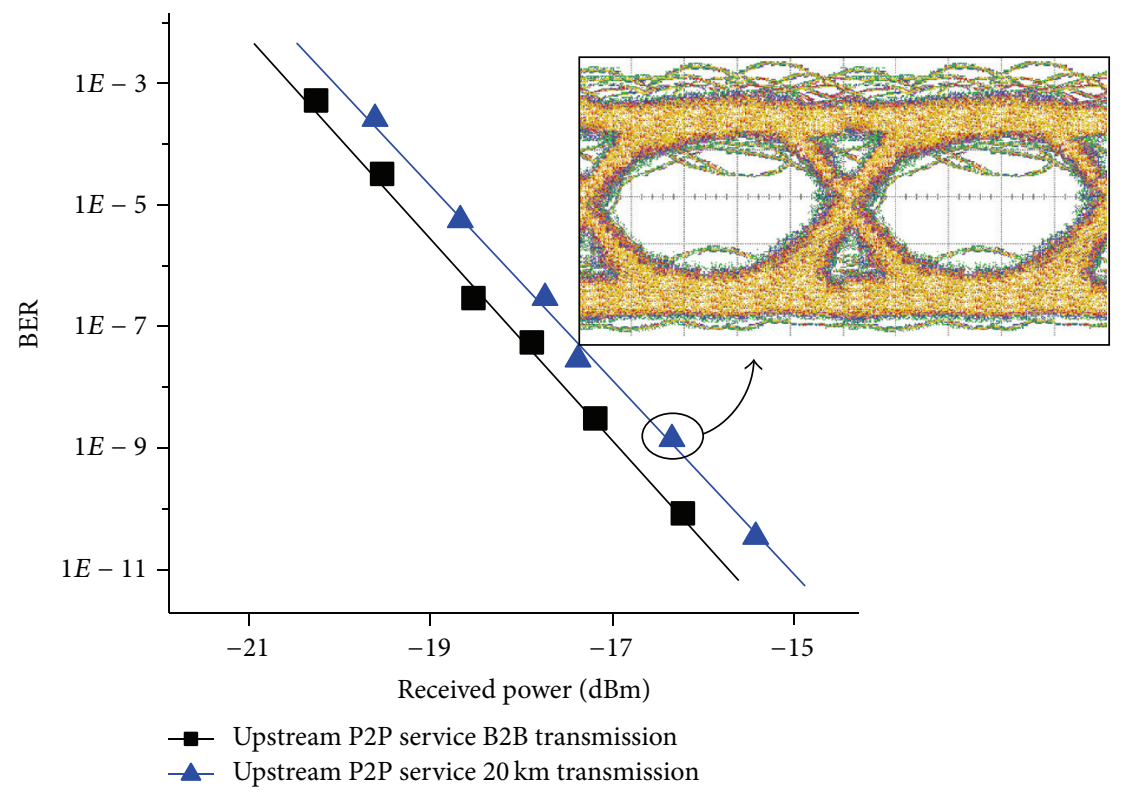

(a)

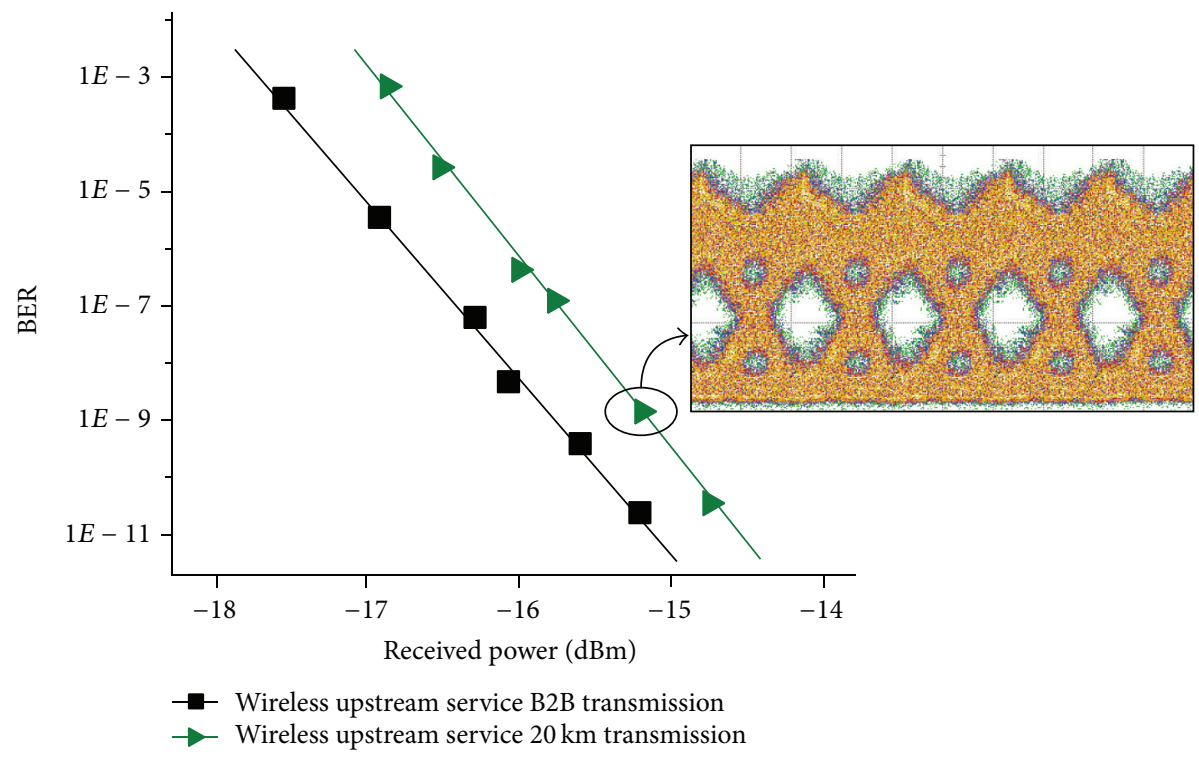

(b)

Figure 5: BER curves and eye diagrams of the two upstream services [8].

\section{Conflict of Interests}

The authors declare that there is no conflict of interests regarding the publication of this paper.

\section{Acknowledgments}

This work is supported by China National Key Technology R\&D Program of the 12th five-year plan under Grant no. 2013BAG19B01 and is partly supported by National Natural Science Foundation of China under Grant no. 61074139 and the Project of Shanghai Science and Technology Committee under Grants no. 12231200103 and no. 14DZ0511300.

\section{References}

[1] K. Satyanarayana and B. Abhinov, "Recent trends in future proof fiber access passive networks: GPON and WDM PON," in Proceedings of the International Conference on Recent Trends in Information Technology (ICRTIT '14), pp. 1-5, IEEE, Chennai, India, April 2014.

[2] K. Prince, T. B. Gibbon, R. Rodes et al., "GigaWaM-nextgeneration WDM-PON enabling gigabit per-user data bandwidth," Journal of Lightwave Technology, vol. 30, no. 10, pp. 1444-1454, 2012.

[3] M. Levesque, F. Aurzada, M. Maier, and G. Joos, "Coexistence analysis of $\mathrm{H} 2 \mathrm{H}$ and M2M Traffic in FiWi smart grid communications infrastructures based on multi-tier business models," 
IEEE Transactions on Communications, vol. 62, no. 11, pp. 39313942, 2014.

[4] M. Morant, R. Llorente, J. Herrera, T. Alves, A. Cartaxo, and M. Herman, "Integrated FTTH and in-building fiber-coax OFDM field trial," IEEE Photonics Technology Letters, vol. 26, no. 8, pp. 809-812, 2014.

[5] G. Witjaksono and I. Saraswati, "Design and analysis of surface emitting distributed feedback (SEDFB) laser for radio-overfiber (ROF)," in Proceedings of the IFIP International Conference on Wireless and Optical Communications Networks (WOCN '07), pp. 1-6, IEEE, Singapore, July 2007.

[6] W. Nai, D. Dong, W. Zheng, and S. Chen, "A novel vehicle-toinfrastructure communication system providing triple play services based on radio-over-fiber technique," in Proceedings of the 7th International Conference on Wireless Communications, Networking and Mobile Computing (WiCOM '11), pp. 1-4, IEEE, Wuhan, China, September 2011.

[7] W. Ji, X. Li, Z. Kang, and X. Xue, "Design of WDM-RoF-PON based on Improved OFDM mechanism and optical coherent technology," IEEE/OSA Journal of Optical Communications and Networking, vol. 7, no. 2, Article ID 7035548, pp. 74-82, 2015.

[8] W. Nai, D. Dong, S. Chen, W. Zheng, and W. Yang, "A centralized lightwave WDM-PON with quintuple services integrated," Journal of Information and Computational Science, vol. 9, no. 16, pp. 4699-4704, 2012.

[9] S.-J. Park, C.-H. Lee, K.-T. Jeong, H.-J. Park, J.-G. Ahn, and K.-H. Song, "Fiber-to-the-home services based on wavelengthdivision-multiplexing passive optical network," Journal of Lightwave Technology, vol. 22, no. 11, pp. 2582-2591, 2004.

[10] W.-F. Zhang, X.-J. Xin, Q. Zhang, Z.-X. Zhang, W. Nai, and Y. Shi, "Centralized light-wave WDM-PON employing DQPSK downstream and OOK remodulated upstream signals," The Journal of China Universities of Posts and Telecommunications, vol. 17, no. 4, pp. 125-128, 2010.

[11] J. Yu, O. Akanbi, Y. Luo et al., "Demonstration of a novel WDM passive optical network architecture with source-free optical network units," IEEE Photonics Technology Letters, vol. 19, no. 8, pp. 571-573, 2007.

[12] M.-F. Huang, J. Yu, H.-C. Chien et al., "A simple WDM-PON architecture to simultaneously provide triple-play services by using one single modulator," in Proceedings of the Conference on Optical Fiber Communication/National Fiber Optic Engineers Conference (OFC/NFOEC '08), Paper OTuI4, pp. 1-3, IEEE, San Diego, Calif, USA, February 2008.

[13] Y. Luo, J. Yu, J. Hu, L. Xu, P. N. Ji, and T. Wang, "WDM passive optical network with parallel signal detection for video and data delivery," in Proceedings of the Optical Fiber Communication Conference and National Fiber Optic Engineers Conference (OFC/NFOEC '07), paper OWS6, pp. 1-3, Anaheim, Calif, USA, March 2007.

[14] W. Nai and D. Dong, "A cost effective multi-services WDMPON employing DPSK/FSK orthogonally modulated downstream and OOK remodulated upstream," in Proceedings of the IET International Communication Conference on Wireless Mobile \& Computing (CCWMC '11), pp. 232-236, IEEE, November 2011.

[15] Y. Tian and Y. Su, "A WDM-PON system providing quadruple play service with converged optical and wireless access," in Proceedings of the 34th European Conference on Optical Communications (ECOC '08), Paper P.6.07, Brussels, Belgium, September 2008.
[16] R. Llorente, M. Morant, E. Pellicer et al., "On-the-field demonstration of quintuple-play service provision in long-reach OFDM-based WDM-PON access networks," in Proceedings of the 39th European Conference and Exhibition on Optical Communication (ECOC '13), paper We.4.F.1, London, UK, September 2013.

[17] H. Al-Raweshidy and S. Komaki, Radio over Fiber Technologies for Mobile Communications Networks, Artech House, Norwood, Mass, USA, 2002.

[18] C. Bock, M. Alcover, and J. Prat, "Hybrid radio-over-fiber WDM/TDM multi service network featuring dynamic resource allocation," in Proceedings of the 7th International Conference on Transparent Optical Networks (ICTON '05), pp. 153-156, IEEE, July 2005.

[19] C.-T. Lin, J. Chen, P.-T. Shih, W.-J. Jiang, and S. Chi, "Ultrahigh data-rate $60 \mathrm{GHz}$ radio-over-fiber systems employing optical frequency multiplication and OFDM formats," Journal of Lightwave Technology, vol. 28, no. 16, pp. 2296-2306, 2010.

[20] A. Chowdhury, H.-C. Chien, S.-H. Fan, J. Yu, and G.-K. Chang, "Multi-band transport technologies for in-building hostneutral wireless over fiber access systems," Journal of Lightwave Technology, vol. 28, no. 16, pp. 2406-2415, 2010.

[21] Y. Yang, C. Lim, and A. Nirmalathas, "Experimental demonstration of multi-service hybrid fiber-radio system using digitized RF-over-fiber technique," Journal of Lightwave Technology, vol. 29, no. 14, pp. 2131-2137, 2011.

[22] L. Zhang, M. Zhu, C. Ye et al., "Multi-service, multi-band, and MIMO data distribution over $60-\mathrm{GHz}$ RoF system for gigabit wireless local area networks," in Proceedings of the Optical Fiber Communication/National Fiber Optic Engineers Conference (OFC/ NFOEC '12), Paper ATh2C, Los Angeles, Calif, USA, March 2012.

[23] S. Rebhi, R. Barrak, A. Hraghi, and M. Menif, "High spectral efficiency multi-band radio over fiber system for next generation network," in Proceedings of the 16th International Conference on Transparent Optical Networks (ICTON '14), pp. 1-4, IEEE, Graz, Austria, July 2014.

[24] C. Liu, L. Zhang, M. Zhu, J. Wang, L. Cheng, and G.-K. Chang, "A novel multi-service small-cell cloud radio access network for mobile backhaul and computing based on radio-over-fiber technologies," Journal of Lightwave Technology, vol. 31, no. 17, pp. 2869-2875, 2013.

[25] H.-C. Cheng, C.-T. Yen, and I.-J. Ding, "Performance enhancement of optical CDMA by differential-phase method for radioover-fiber transmissions," Mathematical Problems in Engineering, vol. 2013, Article ID 901871, 6 pages, 2013.

[26] G. H. Smith, D. Novak, and C. Lim, "A millimeter-wave fullduplex fiber-radio star-tree architecture incorporating WDM and SCM," IEEE Photonics Technology Letters, vol. 10, no. 11, pp. 1650-1652, 1998.

[27] Z. Jia, J. Yu, G. Ellinas, and G.-K. Chang, "Key enabling technologies for optical-wireless networks: optical millimeter-wave generation, wavelength reuse, and architecture," Journal of Lightwave Technology, vol. 25, no. 11, pp. 3452-3471, 2007.

[28] T.-T. Pham, X. Yu, L. Dittmann, and I. T. Monroy, "Integration of optically generated impulse radio UWB signals into baseband WDM-PON," IEEE Photonics Technology Letters, vol. 23, no. 8, pp. 474-476, 2011.

[29] Z. Cao, J. Yu, H. Zhou et al., "WDM-ROF-PON architecture for flexible wireless and wire-line layout," Journal of Optical Communications and Networking, vol. 2, no. 2, Article ID 5405526, pp. 117-121, 2010. 
[30] C. L. Yang, Q. Y. Hung, S. C. Lin, M. H. Chuang, and S. L. Lee, "Demonstration of bidirectional wired and wireless services in integrated optical and wireless system carried by single wavelength lightwave," in Proceedings of the Photonics Global Conference (PGC '10), p. 1, IEEE, Singapore, December 2010.

[31] M. Zhu, L. Zhang, J. Wang, L. Cheng, C. Liu, and G.-K. Chang, "Radio-over-fiber access architecture for integrated broadband wireless services," Journal of Lightwave Technology, vol. 31, no. 23, pp. 3614-3620, 2013.

[32] C. Rodrigues, A. Gamelas, F. Carvalho, and A. Cartaxo, "Evolution of FTTH networks based on radio-over-fibre," in Proceedings of the 13th International Conference on Transparent Optical Networks (ICTON '11), pp. 1-4, IEEE, Stockholm, Sweden, June 2011. 

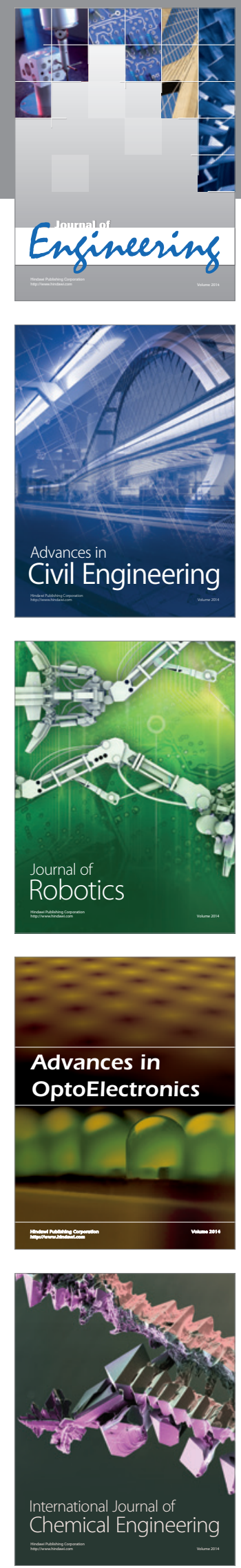

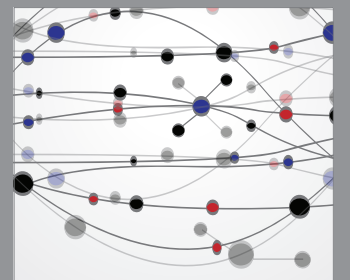

The Scientific World Journal
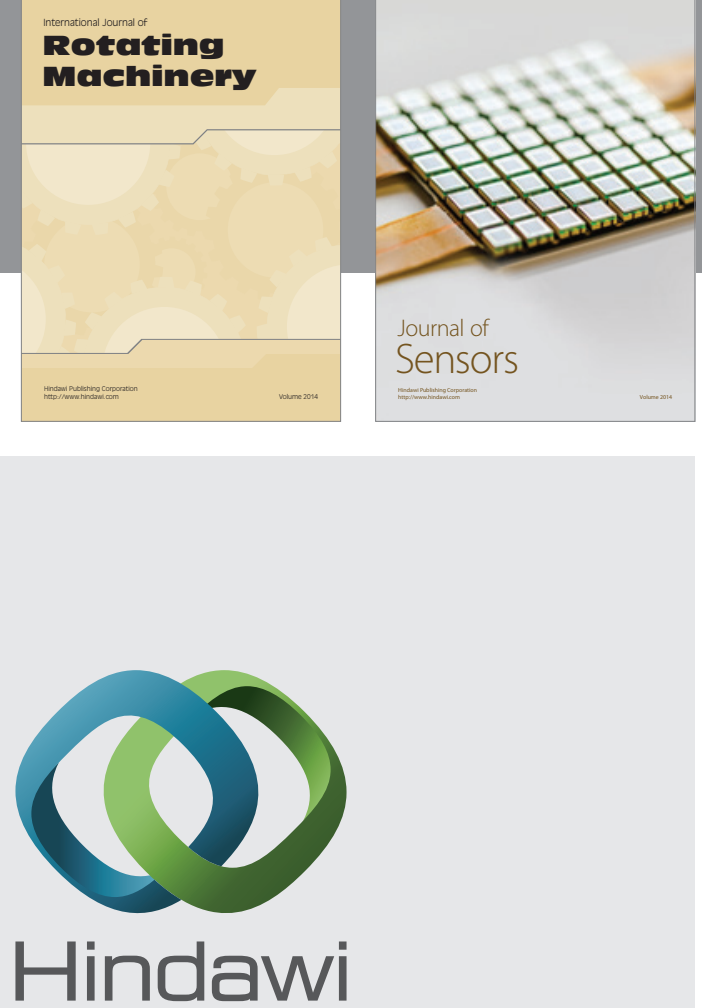

Submit your manuscripts at http://www.hindawi.com
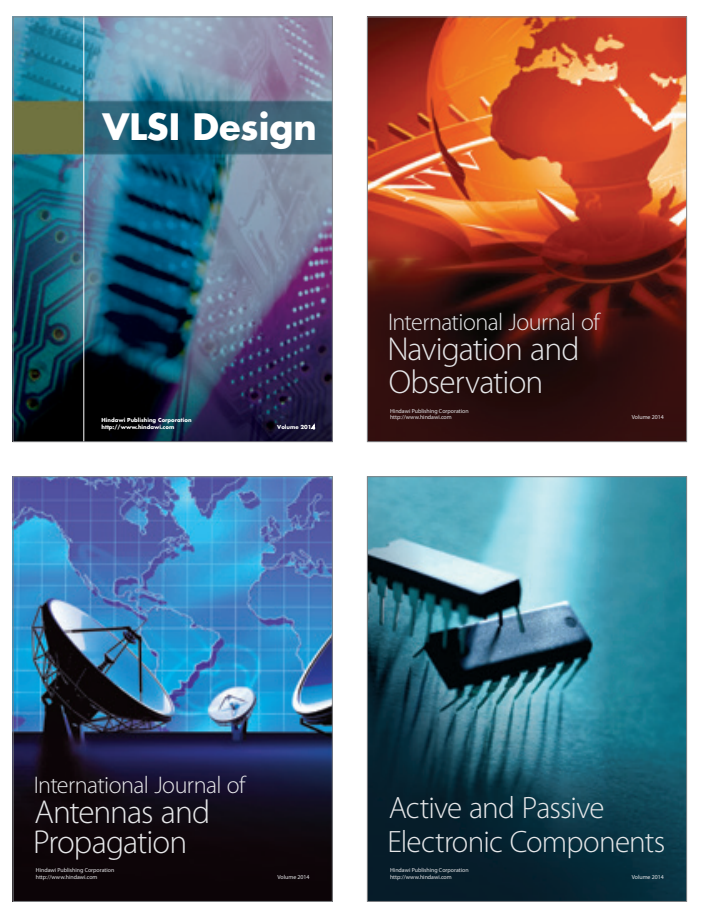
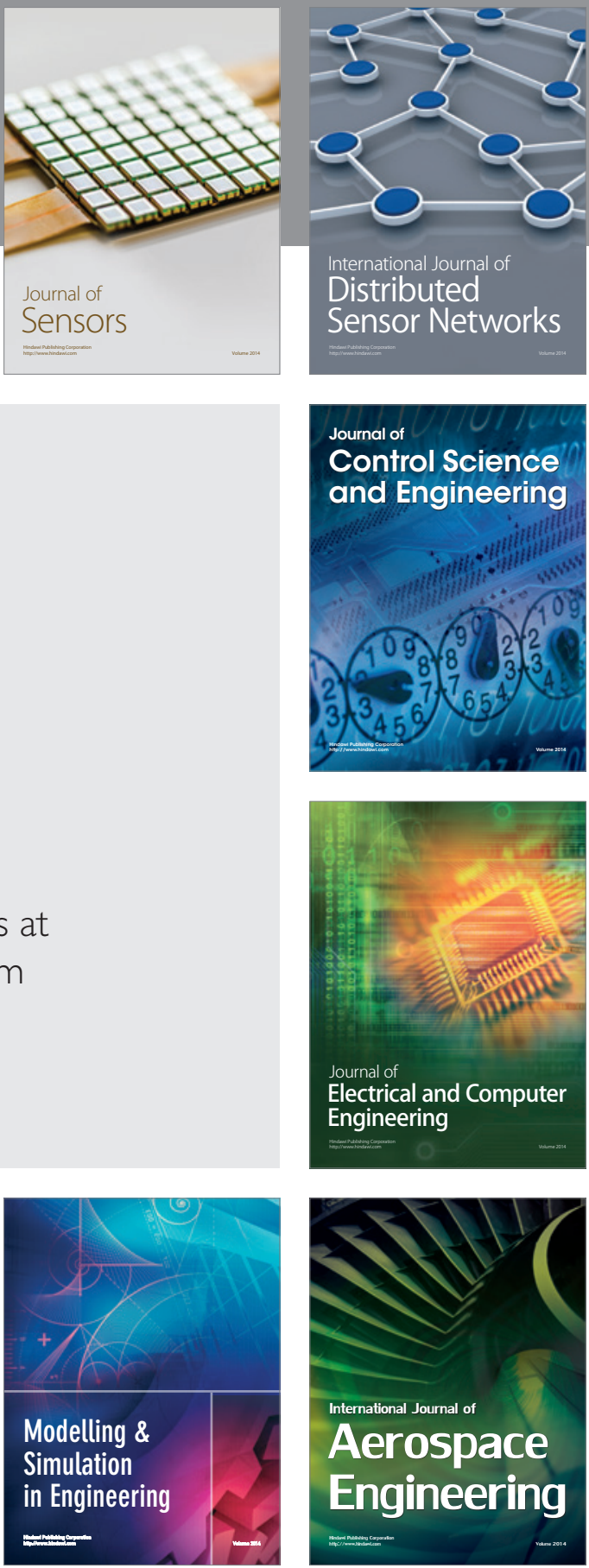

Journal of

Control Science

and Engineering
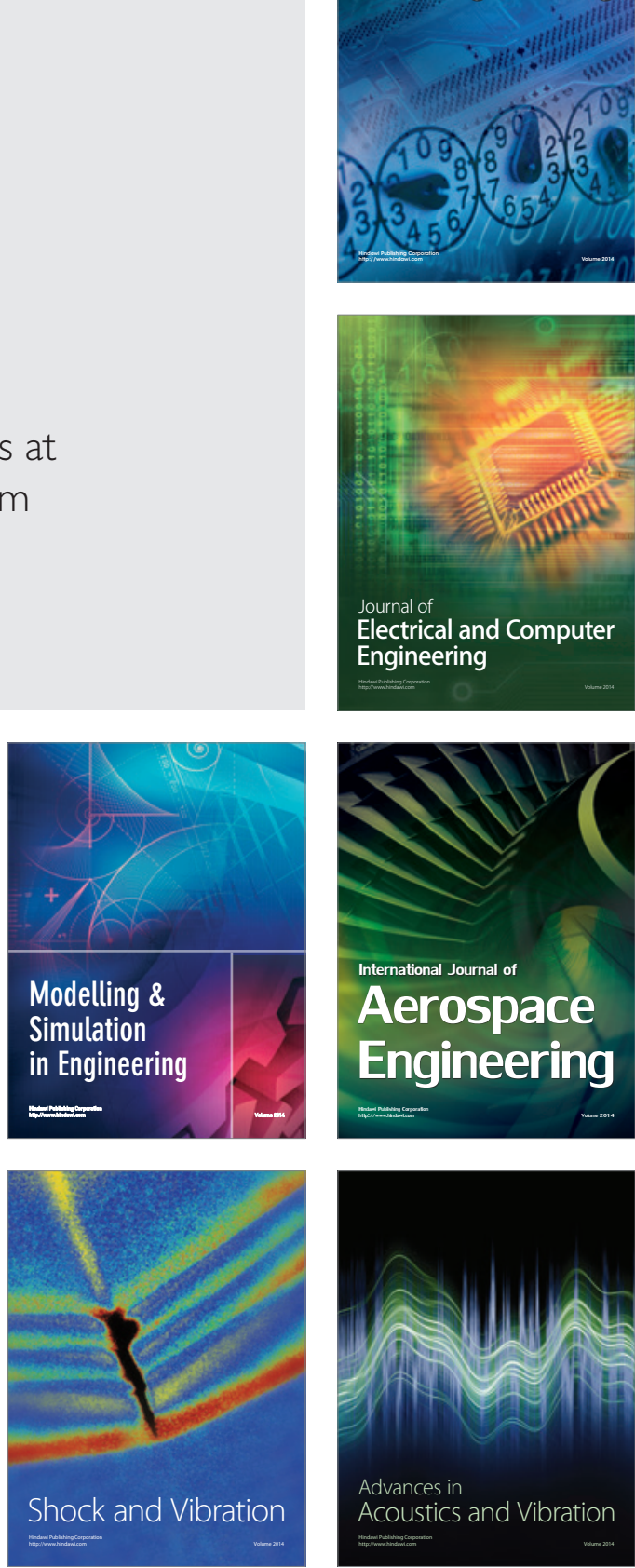